Journal of Economics and Behavioral Studies

Vol. 3, No. 6, pp. 332-336, Dec 2011 (ISSN: 2220-6140)

\title{
Comparing the Volatility Clustering Of Different Frequencies of Stock Returns in an Emerging Market: A Case Study of Pakistan
}

\author{
*Amir Rafique1, Kashif Ur Rehman² \\ ${ }^{1}$ SZABIST Islamabad, Pakistan \\ 2Iqra University, Islamabad, Pakistan \\ *raja_kiyani@yahoo.com
}

\begin{abstract}
This study compares the volatility behavior and variance structure of daily, weekly and monthly returns of the KSE-100 index. The study uses seventeen years data covering the period from 1991 to 2008. By employing ARCH (1) model, the study finds significant asymmetric shocks to volatility in the three series but the intensity of the shocks are not equal for all the series. The study finds that the statistical properties are also substantially different from one another. The stylized fact of volatility clustering is found in the market but is sensitive to the frequencies of data.
\end{abstract}

Keywords: $A R C H$ models, KSE 100-index, volatility clustering.

\section{Introduction}

The publishing of paper on Autoregressive Conditional Heteroskedasticity (ARCH) originated a new debate on stock returns volatility and now the current period is called post ARCH period (Engle, 1982). Researchers, practitioners and policy makers focused on the volatility of stock returns from the point of view of time varying volatility. The volatility in all the financial markets has increased very much in the recent period particularly in the developing markets. After the liberalization of stock market in Pakistan, many researchers started studying the behavior of stock returns. Dawood (2007) investigated the volatility in the Karachi stock exchange and found that after liberalization in 1990's the market has become more volatile as compared to earlier period. He found that the stock market reacts too actively to shocks but this reaction take place on daily basis and die away within a month. Ali \& Akbar (2007) tested the main hypotheses about equality in returns on daily, weekly and monthly basis in Karachi stock exchange and found insignificant results, which means no equality is there among the series.

Many studies show that high frequency data series is more volatile as compared to low frequencies of data. Chang (2006) concluded that mean reversion situation only exists in the low-frequency data. Caiado (2004) also found the same results for Portuguese stock market, where he found asymmetric shocks to volatility in daily stock returns but not for weekly returns. This establishes the need of this study in the developing market of Pakistan. This study fills the gap by examining the volatility pattern for the three data series (daily, weekly and monthly) using stylized fact of volatility clustering. The study objective is "to compare the volatility clustering phenomenon of high (daily) and low (weekly, monthly) frequencies of data".

Pakistan's Capital Market: Karachi Stock Exchange (KSE) was established in $18^{\text {th }}$ September 1947. The other exchanges in Pakistan are the Lahore Stock exchange (est. 1974) and the Islamabad Stock Exchange (est. 1997). KSE is the biggest of the three exchanges where according to an estimate more than $85 \%$ of the trade occurs, and remaining 15\% trade occur in other two markets. Almost 670 companies are listed in KSE having a market capitalization of above US\$95.18 Billion. KSE-100 index is the weighted index of stocks of 100 top market capitalized companies. The growth in the last decade had made KSE the best emerging market of the world. The market was first and third in turnover ratio in 2003 and 2006 respectively.

The unpretentious growth can be observed in the stock market after the liberalization period. During the years 1995-2004, the growth shows a smooth upward curve despite major adverse events. The growth continued for many years and in March 2005, the market broke the barrier of 10,000. Banking, Telecom and Energy sectors contributed heavily in this growth. Due to this immense growth, Business Week classified the KSE as the world's fastest growing market in 2002 and 2004. 


\section{Literature Review}

The variability in stock prices during a period is called volatility (Karolyi, 2001). The volatility follows the heteroskedastic property or time varying process (Turan and Demirtas, 2006). The different frequencies financial data exhibit different properties. As Caiado (2004), used GARCH-type models to measure the volatility for different frequencies of the Portuguese Stock Index (PSI-20) returns and found that some weekly returns properties are substantially different from daily returns. Heteroskedaticity is also present in the developing markets. Rosen (2007) found strong evidence of presence of heteroskedasticity in daily, weekly and monthly returns of Bombay Stock Exchange. Thomas (1995) used GARCH modeling and found autocorrelations, volatility clustering and non-normality in the returns data series. They concluded that ARCH type models are the best to measure these empirical irregularities. McMillan et al (2000) also analyzed the performance of a variety of models and concluded that ARCH type models had most consistent performance than other models.

Volatility clustering is defined as "Some periods of slow and high volatilities" or "Clustering of the variance of the error terms". The size of returns at some point of time is volatility and its long memory is volatility clustering (Eisler, 2007). Caiado (2004) measured the volatility for daily and weekly returns of the Portuguese Stock Index and found support for asymmetric shocks to volatility in the daily returns only. The current period variance of returns had a strong relationship with past innovations (Rosen, 2007). Hassan et al (2000) found the same results for the Dhaka Stock Exchange returns. Papa (2004) analyzed the international stock market volatilities and found volatility clustering in the markets. Volatility clustering is a combination of jumps and smoothly changing components of returns (Maheuy and McCurdyz, 2003). Chowdhury et al (2006) investigated Bangladeshi capital market and found that market returns are influenced by their own shocks. Rizwan et al (2007) investigated the Swedish stock market and found that GARCH models are the best models for measuring volatility. Pasha et al (2007) and Prymachenko (2003) also found that GARCH class models dominate the linear models in measuring volatility. Ali \& Akbar (2007) tested equality in returns on daily, weekly and monthly basis and found that the returns distribution is different for all the series. Dawood (2007) found that in 1990's KSE has become more volatile on both short-term (daily) and medium term (monthly) basis. He found that the stock market reaction to economic shocks take place on a daily basis and die away within a month.

\section{Method}

Data and Sample Period: The daily, weekly and monthly KSE-100 index log returns, rt $=\log ($ It $/$ It-1) is used in the study. The data are taken from the website of finance.yahoo.com and the State Bank of Pakistan. The study employs returns series data from 1991 to 2009 for a total of 4086, 873 and 201 observations, respectively. The data is taken for the period after the liberalization period started in Pakistan because the market was totally dead before that period and after the liberalization period, the market became active. This study used different frequencies of data but the study mainly focuses on the daily observation because it contains more information.

Procedure: The current study employs following methods and models:

- ADF test developed by [9] for testing the hypothesis of null of unit root.

- ARCH (1)

The ADF test is normally applied to check the stationarity of every time series data. The study employs the ARCH model in order to find presence of volatility clustering in the returns series.

\section{Results and Discussion}

The results of the three data series are shown below: 
Table 1: Summary Statistics of Returns Series

\begin{tabular}{lrrr}
\hline \hline & Daily & Weekly & Monthly \\
\cline { 2 - 4 } Mean & .00044 & .002 & .0082 \\
Kurtosis & 8.097 & 5.70 & 5.74 \\
Standard Deviation & .017 & .04 & .10 \\
Jarque-Bera & 4477.30 & 321.46 & 84.14 \\
Observations & 4086 & 873 & 201 \\
\hline \hline
\end{tabular}

\section{Daily Stock Returns}

Table 2: ADF test

ADF Test Statistic

$-25.30$

Table 3: ARCH (1)

Included observations: 4086

\begin{tabular}{|c|c|c|c|c|}
\hline & Coefficient & Std. Error & z-Statistic & Prob. \\
\hline \multicolumn{5}{|c|}{ Variance Equation } \\
\hline ARCH(1) & 0.52 & 0.022 & 24.22 & 0.00 \\
\hline
\end{tabular}

Weekly Stock Returns

Table 4: ADF test

ADF Test Statistic

$-12.99$

Table 5: ARCH (1)

Included observations: 873

Coefficient $\quad$ Std. Error $\quad$ Prob.

Variance Equation

$\begin{array}{lllll}\text { ARCH(1) } & 0.312 & 0.05 & 6.32 & 0.0000\end{array}$

\section{Monthly Stock Returns}

Table 6: ADF test

ADF Test Statistic -5.84

Table 7: ARCH (1)

Included observations: 211

Coefficient Std. Error $\quad$ z-Statistic Prob.
Variance Equation

$\begin{array}{lllll}\mathrm{ARCH}(1) & 0.293 & 0.1045 & 2.804 & 0.0051\end{array}$

The results show that all the data series have positive returns but most of the statistical characteristics of the data are different from one another, so confirming the findings of Caiado (2004), Ali \& Akbar (2007), and Chang (2006). The presence of non-normality in the results confirms the findings of Andersen et al (2001), Magnus et al (2006), Khedhiri and Muhammad (2008), Dickey and Fuller (1979), Thomas (1995), and Turan et al (2006). These characteristics are also observed by Hassan et al (2000) and Li (2007) for the developing markets. This study finds volatility clustering in the Pakistani capital market thus confirms the results of Dawood (2007) and Rashid and Ahmad (2008) for KSE. The ARCH coefficient is higher for the daily data only, 
this confirms the findings of Caiado (2004), Rosen (2007), Peiró (2001), McMillan et al (2000) and Ng and McAleer (2004) used ARCH type models and concluded that the performance of these models is sensitive to the data set. This study also confirms that the volatility measurement is sensitive to the frequency of data.

\section{Summary and Concluding Remarks}

The objective of the study is to compare the volatility of the daily, weekly and monthly frequencies of KSE100 index by applying the ARCH model. A general finding in the literature review is that the emerging markets are more volatile than the developed markets. Another finding is that the high frequency data is more volatile than the low-frequency data. The study concludes that many statistical properties of the three series are different from one another. The daily data are more volatile than the other series, confirming the results of Caiado (2004) and also found volatility clustering in KSE confirming the findings of Dawood (2007) and Rashid and Ahmad (2008) for KSE. The main findings of the study are: The daily data are more volatile than other series and the three series have different properties from one another. The ARCH effects show the presence of volatility clustering in all the series. The ARCH effects are more in the daily data than the low frequencies of data. Low frequency data has less information so the volatility and returns relationship can be best measured by high frequency data.

The above findings of the research have many implications, which are: Volatility measurement gives different results for the different frequencies. The short-term investment decisions should focus on short-term volatility measurement whereas long-term investment decisions require long-term volatility measurement. KSE should set its target as "less volatility with stable returns" for achieving sustained development in the market. The study opens many avenues for the future researches especially in the emerging markets. The breaks in the time series data can be incorporated in the volatility models like modified ICSS technique. Volatility spillovers from one market to other markets and from one industry to other industries should also be studied in future researches.

\section{References}

Ali, S. \& Akbar, M. (2007). Calendar Effects in Pakistani Stock Market. Unpublished Research Paper.

Andersen, T. G., Bollerslev, T., Diebold, F. X. \& Ebens, H. (2001). The Distribution of Stock Return Volatility. Journal of Financial Economics, 61, 43-76.

Caiado, J. (2004). Modeling and Forecasting the volatility of the Portuguese Stock Index PSI-20. Estudos de Gestão - Portuguese Journal of Management Studies, 9(1), 3-21.

Chang, C. H. (2006). Mean Reversion Behavior of Short-term Interest Rate Across Different Frequencies. Unpublished Research.

Chowdhury, S. S. H., Mollik, A. T. and Akhter, M. S. (2006). Does Predicted Macroeconomic Volatility Influence Stock Market Volatility? Evidence from the Bangladesh Capital Market. Working Paper at Department of Finance and Banking University of Rajshahi, Bangladesh.

Dawood, M. (2007). Macro Economic Uncertainty of 1990s and Volatility at Karachi Stock Exchange. Munich Personal RePEc Archive (MPRA), 3219, 07.

Dickey, D.A. and Fuller, W.A. (1979). Distribution of the estimators for auto regressive time series with a unit root. Journal of the American Statistical Association, 74, 427-431.

Eisler, B. Z. (2007). Fluctuation Phenomena on the Stock Market. Unpublished Ph.D. Thesis.

Engle, R. F. (1982). Autoregressive Conditional Heteroscedasticity with Estimates of the Variance of United Kingdom Inflation. Econometrica, 50(4), 987-1007.

Hassan, M. K., Islam, A. M. and Basher (2000). Market Efficiency, Time-Varying Volatility and Equity Returns in Bangladesh Stock Market. Working Paper, Department of Finance and Economics, University of New Orleans.

Karolyi, G. A. (2001). Why Stock Return Volatility Really Matters. Institutional Investor Journals Series, prepared for inaugural issue of strategic investor relations.

Khedhiri, S. and Muhammad, N. (2008). Empirical Analysis of the UAE Stock Market Volatility. International Research Journal of Finance and Economics, 15, 249-260.

Li, J. (2007). Three Essays on Modeling Stock Returns: Empirical Analysis of the Residual Distribution, RiskReturn Relation, and Stock-Bond Dynamic Correlation. Unpublished Ph. D Thesis. 
Maheuy, M. J. and McCurdyz, T. H. (2003). News Arrival, Jump Dynamics and Volatility Components for Individual Stock Returns. Journal of Finance, 59, 755-793.

Magnus, F. J. and Fosu, A. E. (2006). Modeling and Forecasting Volatility of Returns on the Ghana Stock Exchange Using GARCH Models. American Journal of Applied Sciences, 3(10), 2042-2048.

McMillan, D., Speight, A. and Gwilym, O. (2000). Forecasting UK stock market volatility. Applied Financial Economics, 10, 435-448.

Ng, H. G. and McAleer, M. (2004). Recursive Modeling of Symmetric and Asymmetric Volatility in the Presence of Extreme Observations. International Journal of Forecasting, 20, 115-129.

Papa, B. F. (2004). Stock market volatility: A puzzle? An investigation into the causes and consequences of asymmetric volatility. Unpublished Thesis.

Pasha, G. R., Tahira, Q. and Aslam, M. (2007). Estimating and Forecasting Volatility of Financial Time Series in Pakistan with GARCH-type Models. The Lahore Journal of Economics, 12(2), 115-149

Peiró, A. (2001). Skewness in Individual Stocks at Different Frequencies. WP-EC 2001-07: V-1486-2001 IVIE working papers.

Prymachenko, I. (2003), "Stock Price Volatility and its Determinants on the Emerging Financial Market of Ukraine", Unpublished Thesis

Rashid, A. and Ahmad, S. (2008). Predicting Stock Returns Volatility: An Evaluation of Linear vs. Nonlinear Methods. International Research Journal of Finance and Economics, 20, 141-150.

Rizwan, M. F. and Khan, S. (2007). Stock Return Volatility in Emerging Equity Market (KSE): The Relative Effects of Country and Global Factors. International Review of Business Research Papers, 3(2), 362 375.

Rosen, C. (2007). Time Series Econometrics Heteroskedasticity in Stock Return Data: Volume and Number of Trades versus GARCH Effects. Unpublished Thesis.

Thomas, S. (1995). Heteroskedasticity Models on the Bombay Stock Exchange. Working Paper, University of Southern California, Department of Economics.

Turan, G., Bali, K. and Demirtas, O. (2006). Testing Mean Reversion in Stock Market Volatility. Journal of Futures Markets, 28(1), 1-33. 